La

Révolution

française

\section{La Révolution française}

Cahiers de l'Institut d'histoire de la Révolution française

22 | 2022

L'étranger en révolution(s)

\title{
De l'ennemi au nouveau Français : la gestion des étrangers par la police napoléonienne (1799-1814)
}

Jeanne-Laure Le Quang

\section{(2) OpenEdition}

\section{Journals}

Édition électronique

URL : https://journals.openedition.org/lrf/6034

ISSN : 2105-2557

Éditeur

IHMC - Institut d'histoire moderne et contemporaine (UMR 8066)

Référence électronique

Jeanne-Laure Le Quang, « De l'ennemi au nouveau Français : la gestion des étrangers par la police napoléonienne (1799-1814) », La Révolution française [En ligne], 22 | 2022, mis en ligne le 20 janvier 2022, consulté le 23 janvier 2022. URL : http://journals.openedition.org/lrf/6034

Ce document a été généré automatiquement le 23 janvier 2022.

(c) La Révolution française 


\title{
De l'ennemi au nouveau Français : la gestion des étrangers par la police napoléonienne (1799-1814)
}

\author{
Jeanne-Laure Le Quang
}

1 Quinze années durant, la guerre a été une toile de fond omniprésente du Consulat, puis de l'Empire. Cette réalité a lourdement pesé sur la politique intérieure menée par le pouvoir napoléonien ${ }^{1}$. Argument de légitimation, la guerre extérieure est utilisée comme un outil permettant de cimenter l'identité même du régime, autour de l'exaltation d'un «empereur de guerre ${ }^{2}$ ». La rhétorique de la menace permet de déjouer l'image d'un État belliqueux, en soulignant au contraire l'agressivité des monarchies européennes liguées pour l'abattre ${ }^{3}$.

2 Dans ce contexte, la gestion de la présence d'étrangers sur le sol français, et particulièrement, des ressortissants des nations ennemies, constitue un enjeu majeur pour la police napoléonienne. Si les autorités affichent le souhait de réconcilier les Français et de mettre fin aux divisions pour retrouver l'ordre et la concorde, la situation extérieure empêche l'inclusion d'étrangers dans le nouveau corps social. Pourtant, des étrangers demeurent présents en France, qu'ils soient des individus libres - des nobles et diplomates principalement-; ou des prisonniers de guerre envoyés par milliers en France pour une durée limitée.

3 Comment les autorités napoléoniennes gèrent-elles la présence de ces étrangers sur le territoire français ${ }^{4}$ ? À la différence de l'autorité judiciaire, bridée par la nécessité de respecter les règles du droit, la police apparaît comme une institution dédiée à la prévention du risque, chargée à la fois de caractériser la menace et de fournir une réponse à celle-ci, dans un rapport étroit avec l'autorité politique ${ }^{5}$. Pendant le Consulat et l'Empire, la rhétorique militaire rend de fait plus aisée, en la justifiant, l'application de mesures extrajudiciaires, et tend à invalider certains acquis révolutionnaires, notamment en matière de liberté individuelle. La police napoléonienne justifie précisément son action en matière de haute police par l'intensité supposée de la menace pesant sur l'État. Ainsi, en l'an VIII, Joseph Fouché (ministre de la Police 
générale de 1799 à 1810), rappelle dans un compte-rendu aux Consuls que le brigandage dans le Midi, la chouannerie à l'Ouest, mais également la présence à Paris «d'obscurs assassins ", sont attribuables à l'influence souterraine de l'Angleterre ${ }^{6}$. Ce faisant, le ministère de la Police générale remobilise le concept d'« ennemi intérieur ", assimilé à la présence supposée sur le sol français d'individus qui fomenteraient des conspirations en lien avec les ennemis extérieurs; un concept qui sert le renforcement de l'État, puisqu'il justifie des mesures de répression et de mise au pas de la société. «Ennemi intérieur » par excellence ${ }^{7}$, l'étranger présent en France doit dès lors faire l'objet de la plus grande surveillance, des autorités locales jusqu'à l'échelon national - alors que la police est engagée dans un processus de centralisation, visant à uniformiser la prise d'informations sur le terrain pour les concentrer au ministère de la Police générale à Paris. L'étude envisage ainsi plus particulièrement le contrôle des étrangers par le biais des "mesures de haute police ", qui peuvent prendre trois formes complémentaires : la surveillance préventive, l'envoi en détention par «mesure de haute police » (c'est-àdire sans nécessairement de procès préalable), et la surveillance "spéciale », un placement en résidence surveillée ${ }^{8}$.

Cependant, la délimitation même de ce qui est perçu comme "étranger" pose problème, dans le contexte d'un Empire en forte expansion territoriale. Si la période napoléonienne constitue une phase de construction de la définition de la nationalité française sur le plan juridique ${ }^{9}$, la sphère policière s'affranchit de ce droit en chantier pour proposer sa propre grille de lecture et envisager l'étranger en termes d'inclusion et d'exclusion du nouveau corps social, dans une conception pragmatique qui évolue en fonction de la conjoncture internationale - certains étrangers passant, selon les moments, du statut d'allié à celui d'ennemi ou de neutre. Les processus policiers d'identification et de contrôle des étrangers jouent indéniablement un rôle dans l'évolution de la définition de l'« étranger ${ }^{10}$ ». Cette étude entend ainsi reconstituer une typologie des différentes catégories policières concernant l'étranger, pour mieux questionner tant les pratiques de contrôle engagées à leur égard que leur évolution au cours de la période. Diverses archives policières peuvent être convoquées : des milliers de fiches alphabétiques d'individus considérés comme suspects ${ }^{11}$, les bulletins quotidiens adressés par le ministère de la Police générale à Napoléon Bonaparte pour lui rendre un compte journalier de son action ${ }^{12}$, les archives relatives à la gestion des prisonniers de guerre, comme la correspondance policière liée au contrôle des émigrés ou des étrangers tout au long de la période.

Quatre catégories émergent. En premier lieu, l'étranger libre - dont l'archétype est le diplomate noble appartenant aux nations ennemies -, mais aussi le prisonnier de guerre, constituent sans conteste deux facettes de l'«étranger» perçu comme indésirable - bien que leur présence soit tolérée et encadrée par la police napoléonienne. Cependant, l'œil policier porte également sur d'autres catégories d'individus, juridiquement considérés comme Français, mais que la police envisage bien davantage en termes d'extranéité et donc de suspicion. C'est le cas tant des individus vivant dans les nouveaux départements annexés par l'Empire - des «ex-étrangers » devenus sujets impériaux - que des émigrés de retour en France. 


\section{Identifier et surveiller les étrangers résidant en France}

6 Pour opérer une surveillance préventive intense, qui a pour but d'identifier et d'appréhender toute menace à la survie du nouveau régime, la police napoléonienne s'appuie sur un réseau humain et administratif composite. À Paris, le contrôle des étrangers présents dans la capitale est placé sous l'égide de la préfecture de police de Paris créée en l'an VIII ${ }^{13}$. Sur le terrain, la vérification des passeports est confiée aux commissaires de police, quand la surveillance préventive des étrangers est, dans les faits, largement dévolue aux officiers de paix et à leurs inspecteurs. Dans le reste du territoire, les missions policières de contrôle des étrangers sont disséminées entre les mains d'un grand nombre d'acteurs : les commissaires de police - présents seulement dans les villes de plus de 5000 habitants ${ }^{14}$-, la gendarmerie, les autorités municipales, mais aussi, dans les départements côtiers et frontaliers, les commissaires généraux, puis spéciaux, progressivement créés pour renforcer le contrôle sur ces espaces perçus comme sensibles ${ }^{15}$. Ces différentes entités - placées sous l'autorité des préfets, qui doivent eux-mêmes rendre des comptes tant au ministère de la Police générale qu'au ministère de l'Intérieur ${ }^{16}$ - opèrent de façon conjointe, mais souvent concurrente et, parfois, conflictuelle ${ }^{17}$. La complexité de ce maillage révèle le défi d'une gestion policière efficace des étrangers circulant sur le territoire consulaire, puis impérial.

\section{Police et étrangers libres}

7 Le contrôle préventif des individus de nationalité étrangère circulant ou résidant sur le sol français est partiellement codifié18 ${ }^{18}$ Alors que sous le gouvernement révolutionnaire, dans un contexte de guerre, mais aussi de montée en puissance d'un discours xénophobe $^{19}$, tous les étrangers issus des pays en guerre contre la France devaient être arrêtés $^{20}$ et ne pouvaient habiter «Paris, ni les places fortes, ni les villes maritimes, pendant la guerre ", sous peine d'être déclarés hors la loi ${ }^{21}$, après Thermidor, les mesures contre les étrangers s'assouplissent. Sous le Directoire, les étrangers nés dans les pays en guerre peuvent rester vivre en France s'ils y étaient domiciliés avant le $1^{\mathrm{er}}$ janvier 1792, " pourvu qu'ils aient un domicile connu, ou qu'ils soient garantis par quatre des citoyens français domiciliés, et connus par leur patriotisme et leur probité ", les autres devant sortir du territoire ${ }^{22}$. Les ressortissants des pays «amis et alliés de la France " peuvent demeurer en France quelle que soit leur date d'arrivée, s'ils sont «reconnus et avoués " par leurs ambassadeurs. Sous l'Empire, le décret du 22 messidor an XII (11 juillet 1804) confirme la loi du 28 vendémiaire an VI, qui distingue les étrangers admis ou non à fixer leur domicile en France : si les étrangers des pays neutres ou alliés sont tolérés sur le sol français, les étrangers des pays ennemis ne peuvent séjourner en France que s'ils sont sous surveillance et munis d'un passeport ${ }^{23}$. Ils pourront être expulsés du territoire si les autorités jugent leur présence " susceptible de troubler l'ordre et la tranquillité publique ${ }^{24}$ ».

Si cette législation tolère la présence d'étrangers sur le territoire impérial, c'est bien au prix d'une surveillance attentive de leurs faits et gestes, dont témoigne l'amélioration du contrôle des passeports, permettant l'uniformisation de leur surveillance à l'échelle nationale $\mathrm{e}^{25}$. À la frontière, les étrangers doivent échanger leur passeport contre un passe provisoire, délivré par le préfet, le maire ou la police, mentionnant leur destination, alors que le passeport est envoyé au ministère de la Police générale qui le 
vérifie - en le confrontant aux dossiers et registres présents au ministère - avant de le restituer à son propriétaire au moment de son départ de France ${ }^{26}$. Comme le souligne Vincent Denis, le but n'est pas de restreindre les déplacements des ressortissants étrangers, mais de les placer sous surveillance, dans une optique véritablement centralisée, permettant de recouper les informations afin de renforcer la surveillance sur les étrangers jugés suspects. En outre, les hôtels et logeurs en chambre garnie doivent tenir un registre qu'ils sont tenus de présenter au commissaire de police au plus tard vingt-quatre heures après l'arrivée d'un étranger. Ils ont l'obligation de dénoncer l'étranger s'il découche. En outre, tous les voyageurs restant plus de trois jours à Paris doivent être enregistrés chez un commissaire de police puis à la Préfecture. Les informations de ces registres sont centralisées à la préfecture de police de Paris, qui en dresse des états quotidiens transmis au ministère de la Police ${ }^{27}$.

Néanmoins, dès lors que ces mesures sont appliquées avec plus ou moins de zèle selon les endroits et que demeurent cependant fraudes et falsifications, l'efficacité de cette centralisation du contrôle est à nuancer. C'est pourquoi Joseph Fouché réitère régulièrement, dans des circulaires aux préfets, des demandes d'intensification du contrôle de la mobilité des étrangers, réactualisant sans cesse une rhétorique entremêlant ennemi extérieur et intérieur ${ }^{28}$. En faisant des étrangers présents sur le sol français des individus à même d'entretenir des liens avec les nations ennemies, le ministre de la Police recommande une surveillance attentive visant à éclaircir le motif de leur présence, leurs faits et gestes et leurs fréquentations. En l'an VIII, un mois après le début du Consulat, Fouché expédie une circulaire aux autorités départementales pour demander de « retenir tous les étrangers, sous la surveillance des Municipalités, dans l'arrondissement desquelles ils se trouveront, jusqu'à nouvel ordre de ma part ». La missive fait le lien avec le contexte immédiat: selon le ministre, "les revers que nous avons éprouvés en Italie, ont pu forcer [un grand nombre d'étrangers, particulièrement Napolitains et Italiens] à s'expatrier pour se soustraire à la persécution ». Il est également possible que "des agens [sic] des coalisés " se soient "gliss[és] parmi eux ${ }^{29}$ ». Si ce placement en résidence surveillée est alors pensé comme temporaire, des étrangers sont pourtant envoyés en exil intérieur tout au long de la période et, ce, quelle que soit leur nationalité. En l'an X par exemple, la «surveillance spéciale » (c'est-à-dire le placement en résidence surveillée) d'un "Irlandais réfugié » nommé Duckest, est transférée de Mâcon à Lyon, où il a trouvé du travail chez un négociant, sur autorisation de Fouché ${ }^{30}$. Un ancien secrétaire de la légation russe en France, nommé De Kraft, est également en surveillance à Pithiviers, alors que deux frères nommés Trivoli, originaires de l'île de Corfou, sont placés en surveillance à Florence ${ }^{31}$.

10 Dès lors, la surveillance des étrangers présents sur le sol français devient un enjeu crucial de sûreté de l'État. Fouché exige l'envoi régulier par les préfets de statistiques policières ciblées sur les étrangers présents dans leur département, sous forme non pas de chiffres, mais de listes nominatives prenant la forme de tableaux uniformisés, permettant ensuite la centralisation des informations au ministère de la Police générale :

Je vous recommande [...] la surveillance la plus active sur tous les étrangers qui circulent dans votre arrondissement, et plus particulièrement sur les Napolitains et Italiens, vous en ferez dresser un tableau exact, qui contiendra les noms, prénoms, qualités, professions, âges, les noms des lieux de leurs naissance et dernier domicile, et leur signalement, et des observations sur leur conduite, depuis qu'ils 
sont dans votre département, ce tableau indiquera aussi l'époque à laquelle ils y sont arrivés, leurs moyens d'existence, ou le motif de leurs voyages ${ }^{32}$.

Cette exigence de l'enregistrement des étrangers dans des tableaux homogènes doit se comprendre dans le contexte de l'essor de la statistique à l'époque du Consulat ${ }^{33}$, mais elle se place également dans la continuité de la volonté révolutionnaire d'identifier, localiser, classer et ficher les étrangers ${ }^{34}$. Ces données sont ensuite centralisées au ministère de la Police. Les étrangers représentent ainsi $20 \%$ des individus présents dans un fichier de police regroupant plus de 2000 fiches d'individus suspects, soit une forte surreprésentation si l'on songe à leur faible importance numérique dans la société napoléonienne ${ }^{35}$.

À Paris, lieu de concentration d'une surveillance policière renforcée, due à la dangerosité particulière qu'occupe la capitale dans les représentations policières ${ }^{36}$, la surveillance des étrangers connaît une intensité particulière. Les bulletins quotidiens envoyés à Napoléon par le ministère de la Police générale, auxquels nous avons consacré une étude quantitative pour les années 1808-1812, révèlent que les étrangers présents dans la capitale concentrent pendant cette période entre un quart et plus d'un tiers de la surveillance policière parisienne, du moins telle qu'elle est rapportée à l'Empereur ${ }^{37}$.

Individus surveillés à Paris entre 1808 et 1812, nombre de mentions dans les bulletins quotidiens adressés à Napoléon par le ministère de la Police générale

13 En valeur absolue, c'est cette catégorie de population qui y est la plus surveillée, a fortiori entre 1808 et 1810 , où ils constituent, d'après ces bulletins, près de $40 \%$ de la surveillance effectuée à Paris ${ }^{38}$. Ces bulletins sont alimentés par des rapports de police, souvent anonymes ou anonymisés ${ }^{39}$.

La police parisienne surveille en premier lieu les étrangers isolés, qui, parce qu'ils ne sont " avoué[s] ni connu[s] de personne ", deviennent dès lors suspects d'espionnage ${ }^{40}$. En avril 1811 par exemple, l'arrivée à Paris d'un Autrichien nommé Muller, qualifié d'« intriguant» et ayant déjà été détenu au Temple, est scrutée par la police ${ }^{41}$. De même, la fiche de police de Bertrand indique : "Suisse, logé à Paris place des Italiens, hôtel d'Italie ; chargé d'embaucher des ouvriers et des mécaniciens pour les envoyer en Prusse et en Autriche. Il s'était concerté pour cela avec les ambassadeurs de ces deux puissances ${ }^{42} »$. Cette assimilation entre le statut d'étranger et le soupçon d'espionnage touche aussi les étrangers circulant en province, tel Calvi, dont la fiche de police indique :

Napolitain arrêté à Quimper, mendiant sous prétexte d'avoir été ruiné par un tremblement de terre, est déposé à l'hospice de cette ville. L'arrivée à Quimper de cet individu qui y avoit été précédé de deux autres napolitains mendiant de la même manière donna lieu au préfet de penser qu'il pouvoient être des espions, qui sous prétexte de mendicité étoient chargés de quelque mission secrète ${ }^{43}$.

De manière évidente, ici, la dangerosité de l'individu repose uniquement sur le soupçon policier, dû à la conjonction entre condition d'étranger et statut social précaire de cet homme.

En second lieu, les membres des corps diplomatiques présents à Paris concentrent les efforts policiers en matière de surveillance. Ces diplomates ont un statut à part, puisqu'ils n'ont pas vocation à être véritablement intégrés au corps social français, mais demeurent nécessairement, par leur fonction, en marge de celui-ci. Ils constituent 
des acteurs essentiels qui, dans un contexte international tendu, se trouvent susceptibles de relayer des informations de première importance aux ennemis de la France. Le contrôle policier de leurs opinions ainsi que des informations qu'ils propagent apparaît donc essentiel. En 1809, Fouché se plaint par exemple que les étrangers à Paris et les nobles relayent des nouvelles défaitistes sur la guerre d'Allemagne. Un bulletin parle du «caquetage honteux [...] dans les coteries diplomatiques et dans les salons, échos de toutes les sottises de la noblesse [allemande ${ }^{44} »$. Les ambassades russes et autrichiennes font l'objet d'une surveillance quotidienne, notamment au moyen d'indicateurs placés à l'intérieur même de leurs hôtels, ce qui permet l'écoute des conversations privées comme la connaissance de la teneur exacte des papiers se trouvant sur le bureau de l'ambassadeur ${ }^{45}$. Le ministre de la Police entend ainsi connaitre leurs fréquentations, mais aussi l'opinion des gouvernements étrangers à l'égard de l'Empereur, et s'assurer ainsi que les ambassadeurs des différentes nations ennemies (Autriche, Russie, Prusse) ne tiennent pas des conciliabules. Preuve de son importance stratégique, c'est l'inspecteur général du ministère de la Police générale, Veyrat, qui est chargé de cette surveillance ${ }^{46}$.

Les autorités françaises tentent en outre d'influencer l'opinion de ces grands diplomates. Ainsi, à l'arrivée du prince russe Alexis Kourakine à Paris en juin 1810, le gouvernement français organise pour lui des visites des principaux musées de Paris, puis des prisons ${ }^{47}$. De même, la police infiltre, dans les salons fréquentés par ces nobles étrangers, des hommes qui lui sont acquis, afin qu'ils diffusent certaines idées favorables à l'Empereur ${ }^{48}$.

\section{Les prisonniers de guerre, ou la gestion au quotidien de l'ennemi étranger dans la France rurale}

$18 \mathrm{Si}$, dans les plus grandes villes, la gestion policière des étrangers se borne à la surveillance d'individus isolés, dans la France rurale, la présence étrangère est plus forte, bien que largement contrainte. La rétention, pendant la Première Guerre mondiale, d'étrangers ennemis dans des dépôts d'internements, couramment appelés "camps de concentration", est une réalité désormais connue ${ }^{49}$. Cependant, cette pratique existe déjà sous l'Empire: comme le souligne Jacques-Olivier Boudon, les prisonniers de guerre constituent la «manifestation tangible» des victoires remportées par Napoléon, permettant à la France entière d'appréhender la réalité des triomphes de la Grande Armée ${ }^{50}$.

Entre 140000 et 270000 prisonniers de guerre ont fait un séjour en France au cours de l'Empire, si l'on recoupe les différents chiffres avancés par les historiens ${ }^{51}$. Ils arrivent en plusieurs vagues, au fil des différentes campagnes militaires, et demeurent en France jusqu'à la signature de la paix de la campagne en cours, soit quelques mois ou quelques années selon les cas $^{52}$. La gestion de cette importante masse de prisonniers étrangers - Autrichiens, Russes, Prussiens, Espagnols, Napolitains, Suédois - est encadrée par différentes autorités : le ministère de l'Administration de la Guerre, où se trouve un bureau des prisonniers de guerre, mais aussi le ministère de la Police générale, qui entend avoir la main sur leur surveillance ${ }^{53}$. Sur le terrain, c'est la gendarmerie, parfois aidée par la garde nationale ou des compagnies de réserve départementales, qui prend en charge ces étrangers ${ }^{54}$. 
20 Toute la France ou presque est concernée par l'arrivée massive d'étrangers ennemis. Seuls les départements de l'Ouest, les départements frontaliers de l'Est et les départements récemment annexés - géographiquement proches de l'ennemi - en sont quasiment exemptés, ce qui reflète la perception de ces espaces comme particulièrement dangereux aux yeux des autorités policières ${ }^{55}$. Les départements du Nord et de l'Est du pays sont au contraire les plus fortement touchés par ce phénomène : les prisonniers de guerre étrangers sont par exemple nombreux dans le département de Saône-et-Loire, particulièrement les Espagnols (2 800 dans ce seul département ${ }^{56}$ ).

21 La gestion de ces prisonniers de guerre par les autorités françaises et leurs conditions de vie varient selon leur condition - officiers, soldats, forçats. Les militaires du rang sont placés dans des dépôts de prisonniers - anciennes casernes ou couvents le plus souvent -, situés dans les principales villes du département. Au contraire, les officiers sont considérés comme des "prisonniers sur parole» et ne sont pas détenus dans un dépôt, mais attachés à une ville, sous la surveillance d'un officier de gendarmerie, et peuvent louer une chambre ou un appartement ${ }^{57}$. Ainsi, en 1809, il est annoncé que « les officiers autrichiens qui seront fait prisonniers de guerre en Italie seront envoyés à Mâcon pour y résider sur leur parole et sous la surveillance des autorités locales ${ }^{58}$ ». Les officiers étrangers sont libres et peuvent agir à leur guise, sans pouvoir s'éloigner cependant de plus d'une lieue de la ville où ils résident ${ }^{59}$. Alors que les soldats du rang reçoivent quotidiennement une ration de nourriture, les officiers obtiennent des autorités françaises une solde, somme d'argent souvent perçue comme trop modique pour pouvoir tenir leur rang ${ }^{60}$.

22 Enfin, il existe parmi les Napolitains une dernière catégorie de prisonniers, constituée de "forçats ", c'est-à-dire non pas de soldats de l'armée régulière, mais de paysans napolitains qui se sont insurgés contre les Français, condamnés par des tribunaux spéciaux aux travaux forcés ${ }^{61}$. Ces quelques centaines d'hommes, auxquels les autorités impériales ne reconnaissent pas le statut de prisonnier de guerre, sont envoyés en France pour servir de main d'œuvre, avant d'être reconduits à la frontière après leur libération ${ }^{62}$.

23 Mis à part les officiers qui sont traités avec indulgence, les prisonniers de guerre étrangers sont mis au travail, afin de contribuer à la mise en valeur des campagnes françaises. À partir de 1805, en effet, ces prisonniers de guerre acquièrent la possibilité d'aller vivre dans des communes rurales en résidence surveillée, pour travailler chez des particuliers ${ }^{63}$. Les personnes qui souhaitent employer un ou plusieurs prisonniers de guerre dans une ferme ou une manufacture peuvent s'adresser au maire de leur commune, qui s'en réfère au préfet, qui en demande lui-même l'autorisation au ministre de la Guerre.

24 Ces prisonniers sont employés pour les travaux des champs, mais aussi pour des chantiers de travaux publics, comme pour les canaux de Bourgogne, de l'Ourcq et de Niort, ou pour l'assèchement des marais du Rhône et de la Charente. Une lettre du conseiller d'État Pelet de Lozère au préfet de Saône-et-Loire, datée du 11 août 1806, affirme par exemple que « deux mille prisonniers de guerre napolitains ont été mis [...] à la disposition de l'administration des Ponts et Chaussées pour être employés à des travaux publics ${ }^{64} »$. Ces prisonniers sont répartis dans différents départements ${ }^{65}$, notamment en Corse, où des centaines de prisonniers napolitains sont envoyés en 1808 pour mettre l'île en valeur, par la construction de routes ${ }^{66}$. 

fréquentations de ces étrangers. Cependant, la police est pleinement consciente du risque que représente une telle dissémination sur le territoire d'anciens soldats habitués au maniement des armes, susceptibles de garder des liens avec les nations ennemies ou de favoriser la renaissance de troubles. Par conséquent, le ministre de la Police demande en 1808 que ces étrangers soient "sous surveillance spéciale», et « cautionnés par des personnes avantageusement connues ${ }^{67}$ ». On retrouve par exemple dans les archives locales des lettres de cautionnement d'Espagnols écrites par des individus, souvent membres du clergé, se rendant caution de leurs faits et gestes « en matière politique ", ainsi que des lettres de maires attestant de la tranquillité des Espagnols résidant dans leur commune ${ }^{68}$. Les prisonniers de guerre acquièrent dès lors une condition très proche des autres individus placés en surveillance spéciale par la police impériale ${ }^{69}$, puisqu'ils ont interdiction de sortir de la commune qui leur est assignée pour résidence et que leur présence effective dans la commune doit être étroitement surveillée, le règlement de l'an XIV prévoyant notamment que le maire doit faire l'appel tous les dimanches des prisonniers de sa commune ${ }^{70}$.

Une telle main d'œuvre représente une aubaine économique pour les autorités impériales, dans la mesure où ces étrangers prisonniers de guerre reçoivent une rémunération bien moindre qu'un ouvrier français et permettent de diminuer le coût financier de l'entretien de milliers de prisonniers sur le sol impérial ${ }^{71}$. Cependant, cette présence massive d'étrangers pose un enjeu crucial de maintien de l'ordre, puisque nombre de ces prisonniers refusent de travailler et demandent à retourner dans les dépôts, d'où beaucoup parviennent à s'échapper. À partir de 1810, la centralisation du contrôle de ces étrangers se renforce, alors que le ministère de la Police demande aux préfets de recevoir un état des prisonniers de guerre de leur département non plus trimestriel, mais désormais bimensuel, où figureront de surcroît des informations sur «l'esprit qui les anime, les dispositions qu'ils montrent pour les enrôlement volontaires $^{72} »$.

Qu'ils soient libres ou prisonniers, les ressortissants des nations ennemies de la France vivant sur le territoire impérial représentent sans conteste une menace pour les autorités napoléoniennes, une présence qu'il faut tolérer, mais étroitement contrôler même si cette surveillance est fort imparfaite, dans la pratique. Pour autant, la suspicion qui s'attache à la figure de l'étranger ne se limite pas à celles et ceux qui sont natifs d'un pays étranger : les habitants des nouveaux départements et les émigrés sont également deux catégories problématiques aux yeux des autorités consulaires et impériales, ce qui met en lumière les frontières poreuses de la notion d'« étranger ».

\section{Les frontières poreuses de l'« étranger »: nouveau Français et émigré}

\section{Quelle place pour les « anciens » étrangers devenus français dans la France impériale?}

En premier lieu, c'est la place dans le système national des «nouveaux Français » qu'il s'agit d'interroger. Les individus vivant dans les départements annexés par l'Empire entre 1792 et 1810 - au Nord et à l'Est, ainsi qu'en Italie - constituent en effet ce qu'on pourrait appeler des " ex-étrangers ", désormais devenus sujets impériaux. Dans quelle 
mesure sont-ils pleinement intégrés et considérés comme Français par les autorités, alors même que l'identité nationale est encore en construction ${ }^{73}$ ? Si ces départements annexés et leur administration ont fait l'objet de recherches récentes ${ }^{74}$, c'est la vision de ces nouveaux Français par les autorités policières impériales, dans une optique centralisée, qui nous préoccupe ici. De fait, puisqu'ils demeurent dans leur patrie d'origine, ces « ex-étrangers » ne sont pas dangereux par leur circulation, mais par la persistance d'un sentiment de méfiance qui résiste au changement géopolitique et au bouleversement de leur statut officiel.

Le regard porté par la police impériale sur ces étrangers devenus Français révèle une défiance particulièrement forte à l'égard des nouveaux Français vivant dans les départements italiens ${ }^{75}$. De manière révélatrice, dans les archives policières, ces individus sont toujours qualifiés d' «Italiens ", ce qui témoigne de la persistance d'un sentiment d'extranéité à leur égard. Ainsi, les fiches policières de 1931 individus considérés comme suspects comportent 437 individus (23\%) appelés « Italiens » et issus des nouveaux départements annexés par l'Empire en $\mathrm{Italie}^{76}$. Sur les quinze départements concentrant le plus d'individus fichés, quatorze sont des départements italiens ou corses, comme le montre la carte ci-dessous.

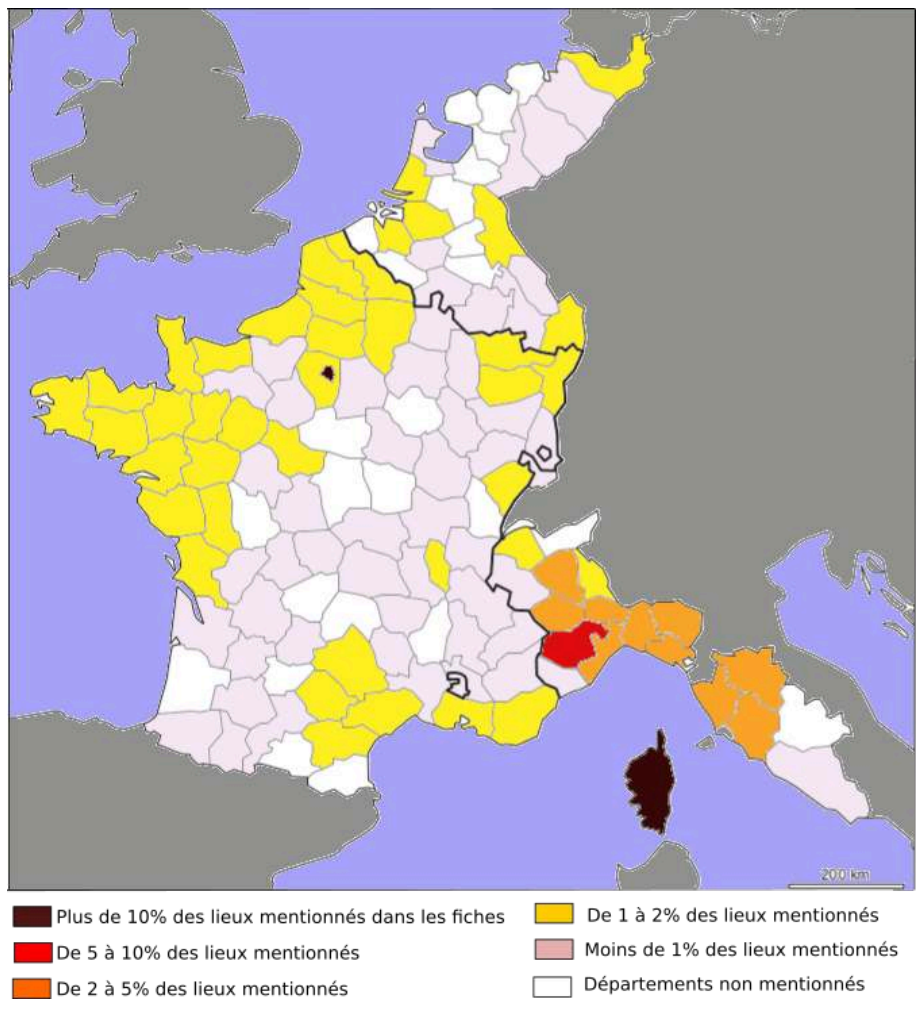

Carte de la surveillance policière à l'échelle du territoire impérial, d'après les fiches de police conservées en AN F7 4260

$\mathrm{Au}$ sein de ces départements italiens, les départements les plus proches de l'ancienne frontière française, des Alpes italiennes à la plaine du Pô, concentrent le plus grand nombre d'individus considérés comme suspects. Ces hommes sont issus de toutes les couches sociales, du notaire, avocat ou chirurgien, jusqu'au cultivateur journalier, mais il faut noter la présence d'un grand nombre d'anciens militaires parmi les Italiens fichés, ainsi que de nombreux membres du clergé (prêtres, moines, etc.). 
31 Cette très forte proportion des nouveaux départements italiens annexés dans les fiches de police vient questionner la difficulté, pour l'État napoléonien, de tenir sa périphérie, mais révèle aussi la persistance d'un regard policier particulièrement aigu sur cet espace et sa population. Le compte-rendu que Fouché adresse aux Consuls en l'an VIII sur l'action de sa police témoigne déjà d'une focalisation policière sur les départements réunis ${ }^{77}$. Le ministre y évoque en effet "les départements qui avoisinent l'Italie »probablement les départements fraîchement annexés du Léman, du Mont-Blanc et des Alpes-Maritimes - comme les lieux où, la Vendée étant «tranquille », se tiendraient les agitations les plus virulentes, faites de " haines », de « vengeances » et d'« assassinats ». Il fait état du succès de ses premières mesures pour ramener l'ordre public dans ces départements. Quelques années plus tard, les départements italiens concentrent toujours l'attention policière. En l'an XIII, Fouché exige qu'avant d'accorder des passeports pour l'Italie, les préfets lui «référe[nt] des demandes des individus turbulents, tarés et qui auroient figuré dans les troubles ${ }^{78}$ ».

La suspicion policière s'exerce sans doute le plus intensément dans les années qui suivent l'annexion de ces départements à la France. En effet, $68 \%$ de ces fiches sont créées entre 1806 et 1809 , suite au rattachement de ces départements italiens, ce qui explique en partie la surreprésentation de ces départements dans la cartographie policière des lieux dits sensibles, puisqu'ils constituent alors ce qu'Aurélien Lignereux a appelé un "front chaud rébellionnaire ${ }^{79}$ ». De fait, les individus issus des nouveaux départements italiens représentent plus de la moitié de ceux fichés pour des faits relevant de la délinquance ordinaire. La surveillance préventive dont témoignent ces fiches de police a donc pour enjeu de ramener l'ordre public dans ces nouveaux territoires, en soustrayant à la population - par l'envoi en détention par «mesure de haute police » ou en surveillance spéciale - les individus les plus turbulents, potentiels acteurs de soulèvement politique contre le nouveau régime. Cette surveillance de « haute police » est donc complémentaire de l'action, sur le terrain, de la gendarmerie, qui tient dans ces espaces un rôle essentiel afin de contenir les actions criminelles, et, in fine, de parvenir au ralliement de l'opinion publique locale ${ }^{80}$.

Les Italiens faisant l'objet d'une nouvelle fiche de police se situent très souvent dans les départements les plus récemment annexés. C'est le cas d'Antoine Biggi, arrêté en 1809 dans le département du Taro - annexé en 1808 - comme "vagabond, mauvais sujet, arrêté plusieurs fois pour prévention de vol», ou de Joseph Buzzo, arrêté en 1806 comme menant " une vie qui ne laissoit aucun doute de ses liaisons avec les brigands » dans le département de Gênes, annexé là aussi l'année précédente ${ }^{81}$. On peut aussi citer le cas de Jean-Baptiste Prigioni, marchand de liqueurs à Livourne - chef-lieu du département de Méditerranée, annexé en 1808 -, arrêté début 1809 parce que "sa maison était depuis quelque temps le point de réunion de tous les mécontens [sic], qui parlaient contre les Français avec une indécence et une audace très répréhensible » et parce qu'il répand en temps de guerre de fausses nouvelles contre la France ${ }^{82}$. Dans l'œil de la police s'entremêlent donc plusieurs motifs de suspicion permettant de considérer les nouveaux Français vivant en Italie comme d'une dangerosité particulièrement vive: des motifs de délinquance ordinaire (vol, brigandage, vagabondage), mais aussi des propos ou actes séditieux, faisant de ces individus une menace politique pour la survie même de l'État. Outre le soupçon de brigandage ou d'acte séditieux "anti-français", l'espionnage constitue ainsi un autre motif de suspicion dominant dans les fiches policières: une proportion importante de ces 
«nouveaux Français » italiens sont perçus comme dangereux pour leur lien supposé avec l'Angleterre, l'Autriche ou le roi de Sardaigne.

La gestion policière des régions conquises vise donc à placer sous surveillance ou à envoyer en détention par « mesure de haute police » tout individu qui pourrait y causer du trouble. Deux prisons d'État, Compiano et Fenestrelle, situées dans les départements italiens annexés, sont dédiées aux prisonniers d'État qui en sont issus - avec en partie des détenus religieux, tel le cardinal Pacca, conseiller particulier du pape ${ }^{83}$. L'importance numérique de ces détenus italiens est à souligner. Selon Jean-Claude Vimont, ils représentent près d'un tiers des prisonniers d'État ${ }^{84}$, ce qui révèle combien la menace extérieure, incarnée par ces nouveaux Français, représente une obsession pour la police impériale et pour l'Empereur. Sur les 612 individus écrivant à la Commission sénatoriale de la liberté individuelle, créée en 1804 pour donner aux Français des garanties contre toute détention arbitraire (mais largement inefficace dans les faits ${ }^{85}$ ), 32 , soit $5 \%$, sont des Italiens ${ }^{86}$.

Les nouveaux départements annexés du Nord-Belgique, Hollande, rive du Rhinsemblent l'objet d'une moindre attention policière, dans la mesure où le fichier national de police mentionne peu de suspects qui en sont originaires. Ils ne sont cependant pas absents de cette surveillance préventive et demeurent des «lieux sensibles » de l'espace impérial - en témoigne une mission de Réal (conseiller d'État chargé du premier arrondissement de police) en Belgique et en Hollande, en 1809, pour y surveiller l'esprit public ${ }^{87}$. D'autres sources témoignent de la permanence, dans ces nouveaux départements annexés du Nord, d'une insoumission relative à l'Empire, ou du moins, de la persistance de troubles ${ }^{88}$. La faible présence de ces nouveaux départements du Nord dans le fichage policier témoigne peut-être surtout de la géographie mentale d'une police qui verrait les départements du Sud comme bien plus sensibles, puisqu'ils sont davantage liés à des nations ennemies.

Enfin, plusieurs nouveaux Français sont placés en surveillance spéciale, c'est-à-dire en résidence surveillée, sous contrôle des autorités locales, avec interdiction de s'éloigner de leur lieu de relégation. C'est le cas dans les nouveaux départements du Nord, dès l'an VIII - avec neuf individus en surveillance spéciale dans le département de la Dyle et cinq dans l'Ourthe -; puis, en 1810, avec 53 individus en surveillance spéciale dans l'ensemble des départements récemment annexés du Nord-dont treize dans le département de la Lys, treize également dans les Deux-Nèthes et neuf dans le MontTonnerre. Certains de ces « ex-étrangers » sont parfois envoyés en surveillance spéciale très loin de leur département d'origine, dans la "vieille France ", ce qui révèle leur dangerosité aux yeux de la police. En Saône-et-Loire par exemple, sur les 88 individus placés en surveillance spéciale, on peut noter la présence de quatre Belges - prévenus d'avoir «servi les Anglais lors de leur séjour à Valcheren»-, un Italien et un Allemand ${ }^{89}$. Dominique Rosini, frère laïc, est aussi envoyé en surveillance spéciale de Rome jusqu'à Auxerre (Yonne) en 1809, tout comme Camille Simeone, évêque, issu de la région de Viterbe, est envoyé à Belley (Ain) en 1810 pour avoir refusé de prêter serment ${ }^{90}$.

Si «anciens" comme «nouveaux» Français sont soumis aux mêmes mesures préventives de "haute police " (surveillance, envoi en détention sans jugement), la forte proportion des «nouveaux Français " parmi les cibles de ces mesures démontre que ces hommes sont considérés comme particulièrement dangereux aux yeux de la police et révèle ainsi les limites de leur intégration à l'identité nationale. Ils sont 
toujours considérés de facto comme des étrangers, de potentiels agents de l'ennemi, œuvrant au renversement de l'Empire : nombre de ces nouveaux Français reçoivent dans leur fiche de police le qualificatif d'«ennemi de la France» ou d'« ennemi des Français ».

\section{Quand le Français devient étranger : émigrés et « agents de l'ennemi »}

Si c'est la dangerosité supposée des nouveaux Français qui empêche leur totale assimilation au corps national impérial, il en est de même pour certains habitants de la "vieille France ", qui, en vertu des soupçons qui pèsent à leur égard, deviennent dans les faits d'«impossibles citoyens ${ }^{91}$ ». Il s'agit des émigrés rentrés en France, que la police napoléonienne continue à percevoir comme dangereux, par les relations qu'ils ont pu nouer avec les pays ennemis de la France. C'est ce lien supposé avec l'Étranger avec une majuscule qui dénationalise en quelque sorte ces personnes pourtant françaises de naissance, pour les rejeter dans un statut d'« étranger » inassimilable et indésirable, puisqu'ils nuisent à la fois à la cohésion sociale et à la survie de l'équilibre fragile sur lequel repose le pouvoir. On rejoint là le concept d'« étranger politique " proposé par Sophie Wahnich pour la période révolutionnaire pour qualifier l'individu né en France qui, par ses actes ou ses pensées, se place de lui-même hors de l'amitié et hors de la cité et devient un traître méritant la mort.

Si, à partir du décret du 9 octobre 1792, les émigrés sont décrétés "morts civils", " non-sujets de droit » et jugés indignes d'être des citoyens français ${ }^{92}$, sous le Consulat et l'Empire, officiellement, la perception de cette catégorie sociale a fortement évolué par rapport à la période révolutionnaire. Dans la continuité du Directoire, qui a radié 14000 émigrés, toujours dans une optique de "réconciliation nationale ", Bonaparte poursuit les radiations d'émigrés ${ }^{93}$, qui commencent à rentrer en masse dès 1800 , avant de décréter l'amnistie des émigrés, par le sénatus-consulte "relatif aux émigrés » du 6 floréal an X (26 avril 1802). Cette amnistie est possible sous un certain nombre de conditions, notamment de renoncer définitivement à ses biens (même invendus), ainsi qu'à toutes fonctions, titres et décorations reçues à l'étranger, et, surtout, de prêter serment « d'être fidèle au Gouvernement établi par la Constitution, et de n'entretenir, ni directement ni indirectement, aucune liaison ni correspondance avec les ennemis de l'État ${ }^{94}$ ». Cette formulation, intégralement recopiée sur les certificats d'amnistie délivrés aux émigrés, révèle combien la dangerosité des émigrés, pour la police, repose non pas seulement sur leurs opinions royalistes, mais également sur les liens qu'ils entretiennent avec l'étranger. Un bureau des émigrés est créé au sein du ministère de la Police, dirigé par le citoyen Desages, ainsi qu'une commission des émigrés, sous la tutelle du ministre de la Justice.

Pourtant, malgré ces mesures d'amnistie, le pardon impérial n'induit pas une liberté totale pour les anciens émigrés. Le sénatus-consulte excepte de l'amnistie certains hommes (les chefs de rassemblements armés notamment). De surcroit, même l'émigré amnistié demeure fortement suspect aux yeux du régime. Le Code pénal de 1810 prévoit de fortes peines, allant jusqu'à la mort ou le bannissement, pour «quiconque aura pratiqué des machinations ou entretenu des intelligences avec les puissances étrangères ou leurs agents ${ }^{95} »$. Cependant, en pratique, il est moins question de mise à mort de ces « étrangers politiques » que de leur placement sous intense surveillance, au 
moyen des mesures de haute police. Le même Code prévoit que l'émigré doit être placé en surveillance pour une durée de dix ans, avec la possibilité d'être éloigné de vingt lieues de son domicile habituel ${ }^{96}$. Cependant, cette surveillance "spéciale " a été mise en place de facto dès messidor an VIII, par un arrêté des Consuls pris sur demande de Fouché, dont un rapport insiste sur la nécessité de se conduire "avec réserve et précaution envers les individus qui ont des droits à leur radiation et qui l'obtiennent ${ }^{97} »$. Le rapport argue notamment de la dangerosité persistante de ces hommes qui, malgré leur radiation, ne sont pas toujours bien intentionnés vis-à-vis du nouveau régime, n'étant pas «assez généreux pour oublier des maux qui furent pour eux inévitables » et nourrissant rancœur et ressentiment face à la perte de leurs biens. Second argument, les «craintes que les prévenus d'émigration absous ou incertains encore de leur sort, inspiraient à une masse aussi respectable qu'immense de propriétaires, tantôt en les inquiétant par des menées indirectes et par des prétentions habilement dissimulées, tantôt en les menaçant avec audace ${ }^{98}$ ". Par conséquent, empêcher les anciens émigrés, en les plaçant en surveillance, de porter "allarmes [sic] » et "troubles ${ }^{99}$ ", d'inquiéter les propriétaires de biens nationaux et donc de menacer la tranquillité publique est, pour le ministre de la Police, une mesure dont il souligne la justice, insistant sur le fait que c'est l'œuvre d'un gouvernement soucieux de l'intérêt de tous. Par cet arrêté, de fait, les émigrés, même radiés, voient toute réintégration au corps national impossible. Ils demeurent perçus de facto comme inassimilables.

41 Tout au long de la période, le ministre de la Police envoie régulièrement des circulaires aux préfets pour leur rappeler de ne pas diminuer leur surveillance sur cette classe d'individus ${ }^{100}$. Pour les qualifier, il n'utilise jamais le terme de «Français », mais, la plupart du temps, celui de " prévenus d'émigration » ou d'« individus qui ont des droits à leur radiation ». La suspicion semble en outre se réactiver quand la France reprend la guerre contre ses voisins ${ }^{101}$. Dans ces circonstances exceptionnelles, l'émigré redevient en puissance l'agent de l'ennemi, l'espion de l'étranger et sa perception comme Autre, étranger, est réactivée. Par conséquent, il est décidé de renforcer la régulation de la sortie du territoire de ces hommes et ces femmes, en restreignant la délivrance de passeports aux "émigrés qui justifieront d'une manière non douteuse, que leur présence y est indispensablement nécessaire ${ }^{102} »$. De plus, au moment de leur retour en France, ils devront "présenter pour garantir leur soumission, le cautionnement de deux citoyens connus qui ne soient ni amnistiés ni émigrés ${ }^{103}$ ».

De fait, jusqu'à la fin de l'Empire, les émigrés sont soumis à une surveillance policière attentive. $14,7 \%$ des fiches de police étudiées mentionnent le fait d'émigration comme principal motif de suspicion policière, soit 295 individus sur $2001^{104}$. Sont ainsi fichés des individus radiés, mais toujours perçus avec suspicion, comme le sieur Tschudi, à Metz, dont la fiche indique qu'en 1808, on a demandé sur son compte des renseignements au ministre de la Police du royaume de Naples, puisque cet ancien émigré « servoit en France [avant la Révolution] dans un régiment allemand, mais qu'il avoit émigré en 1790, et avoit passé au service de Naples ». Les bulletins quotidiens envoyés à Napoléon par le ministère de la Police générale mentionnent également la surveillance des émigrés arrivant à Paris, qu'ils soient radiés ou non. Le bulletin du samedi 23 juin 1810 indique par exemple que

le ministre a fait arrêter les dames Montalembert, Podenas, Huc, De Cottes et le mari de cette dernière, tous venant de Londres par Dieppe. [...] Les dames Podenas et Montalembert sont envoyées en surveillance à 40 lieues de Paris, M. et Mme De 
Cotte restent provisoirement en surveillance spéciale à Paris sous la caution de M. le sénateur Sémonville et pour donner les explications nécessaires sur leurs papiers $^{105}$. en détention par «mesure de haute police ». Exemple révélateur, le dossier de Joseph Hyacinthe de Montaignac et, notamment, les renseignements collectés sur son compte par le préfet de police Dubois :

Montaignac, ancien Maréchal de camp, émigré amnistié, qui, arrêté au mois de janvier dernier, comme prévenu de correspondance avec les ci-devant princes français ou leurs affidés, fut déposé d'abord à la Force et ensuite envoyé en surveillance au Mans département de la Sarthe. Aussitôt son arrivée à Paris, je l'ai fait surveiller avec le plus grand soin, et ce n'est pas sans étonnement que j'ai appris que, loin de se repentir de ses erreurs, il cherchoit à renouer ses intrigues, et à établir une nouvelle correspondance avec Louis 18 ou ses principaux agents. [...] Le Sr Montaignac, malgré son âge de 73 ans et des infirmités de toute espèce, n'en est pas moins un homme dangereux. La leçon qu'il a reçue a été inutile; et l'indulgence dont on a bien voulu user à son égard, n'a rien changé à ses opinions, ni à sa conduite, et c'est véritablement un être incorrigible. J'estime en conséquence qu'il y a lieu de le déposer au Temple jusqu'à nouvel ordre ${ }^{106}$.

Malgré son âge avancé et son infirmité, Montaignac a, aux yeux de la police, brisé le pacte nouveau qui l'unissait à l'Empire, en tentant de renouer ses liens avec l'étranger. La promesse d'une amnistie lui assurant une vie sous surveillance, mais libre, ne peut être tenue. Dans un contexte de guerre européenne, le champ lexical du rapport policier - « homme dangereux », « c'est véritablement un être incorrigible » - témoigne du caractère irrémissible de la dangerosité de cet ancien émigré, justifiant sa détention par «mesure de haute police» sans passage devant les tribunaux, et le rejetant hors de la communauté nationale ${ }^{107}$. C'est donc bien une «condition d'extranéité ${ }^{108}$ " qui caractérise les émigrés sous l'Empire, bien qu'ils soient théoriquement des citoyens français à part entière.

\section{Surveillance policière et événements extérieurs : évolutions du contrôle de l'étranger au cours de l'Empire}

La gestion policière des étrangers sous le Consulat et l'Empire n'a, enfin, rien de monolithique. S'interroger sur les fluctuations du contrôle policier au cours de la période permet, en dernier lieu, d'affiner les contours de la perception de l'étranger par les autorités napoléoniennes dans un contexte de crise croissante.

L'examen de la nationalité des étrangers surveillés dans Paris, telle qu'elle est rapportée dans les bulletins du ministère de la Police adressés à Napoléon entre 1808 et 1812 , montre à la fois la concentration de la surveillance sur les ressortissants des pays en guerre contre la France et l'évolution de cette surveillance en fonction des circonstances extérieures.

Ce sont les ressortissants des pays contre lesquels la France est en guerre qui concentrent la surveillance à Paris: les Russes (près de $50 \%$ des mentions de la surveillance d'étrangers dans les bulletins de police entre 1808 et 1812), les Autrichiens et les Espagnols, représentent les étrangers les plus surveillés. Paradoxalement, on retrouve peu d'Anglais placés sous l'œil policier dans la capitale, probablement du fait 
de la faible présence de cette nationalité sur le sol français et de l'interdiction de leur circulation dans le territoire; tous les Anglais présents en France, à partir du décret du 2 prairial an XI (22 mai 1803), devant être arrêtés comme prisonniers de guerre, dans un contexte de guerre imminente avec l'Angleterre. Si quelques ressortissants anglais obtiennent des exemptions, on ne trouve donc quasiment pas d'Anglais circulant librement dans le territoire français.

Cette surveillance des étrangers évolue selon le contexte extérieur. Ainsi, les bulletins quotidiens envoyés à Napoléon par Fouché, puis Savary, révèlent l'existence de pics de surveillance policière à Paris pendant les périodes de guerre. Par exemple, à la suite de l'entrevue d'Erfurt entre le tsar russe et Napoléon en octobre 1808, qui renouvelle l'alliance franco-russe, les bulletins quotidiens révèlent une forte augmentation de la surveillance des Russes présents dans la capitale pendant près d'un $\mathrm{an}^{109}$. La surveillance de ces étrangers est donc le reflet de la méfiance du gouvernement, qui sait la précarité de cette alliance militaire et diplomatique.

Le contexte diplomatique entre également en jeu: à Paris, les Espagnols sont étroitement surveillés entre octobre et décembre 1808, au moment où ils doivent prêter serment à Joseph Bonaparte (roi d'Espagne depuis juin 1808). À partir d'un recensement donné par l'Ambassade, les bulletins quotidiens dressent ainsi des listes de noms de ceux qui prêtent serment et surveillent ceux qui s'y refusent. Cette surveillance décroît ensuite jusqu'à juin 1809, sans disparaître totalement: les Espagnols présents à Paris continuent à être " observés ", la police prenant sur chacun d'eux des «informations particulières ${ }^{110}$ ». En province, au même moment, Fouché ordonne l'arrestation de tous les Espagnols présents sans passeports ou qui, «par leur conduite ou leurs relations, peuvent être considérés comme suspects ${ }^{111}$ » et demande aux préfets de dresser un état de tous les Espagnols présents dans leur département, avec indication de leur qualité, du motif et de l'époque de leur voyage en France et de la décision à leur égard, dans le même souci statistique d'enregistrement des suspects.

Constituant une moindre menace aux yeux de la police, les ressortissants des autres pays font l'objet d'une surveillance beaucoup plus éparse à Paris. C'est notamment le cas des Portugais, dont le pays fait l'objet de trois tentatives d'invasion par les forces impériales françaises - en 1807-1808, en 1809, et en 1810-1811. Les seules mentions de surveillance de Portugais à Paris ont lieu lors de la première et la troisième invasion pendant lesquelles des mouvements de résistance se développent. Ainsi, le ministre des Relations extérieures écrit au ministre de la Police le 5 janvier 1808 : «je crois devoir observer que le Portugal s'étant soumis sans résistance, les sujets de cette nation ne peuvent être considérés comme ennemis. De simples mesures de surveillance me paraissent suffisantes à leur égard ${ }^{112}$ ». En dehors de ces moments de crise, les Portugais sont peu surveillés à Paris. Par ailleurs, alors qu'ils étaient considérés comme particulièrement dangereux par les autorités policières au début du Consulat, peu d'Italiens et de Napolitains sont surveillés à Paris entre 1808 et 1812, ce qui s'explique à la fois par un changement de regard sur les Italiens issus des zones désormais annexées, qui sont devenus de "nouveaux Français » et par un retour des Napolitains dans leur patrie en 1806.

51 Le contexte militaire ou diplomatique extérieur influe, de la même manière, sur la gestion policière des prisonniers de guerre. Ainsi, en frimaire an XIV (décembre 1805), Pelet de la Lozère écrit au préfet de Saône-et-Loire pour lui annoncer la décision d'envoyer dans son département 4720 prisonniers de guerre autrichiens, lui 
recommander de s'occuper de la distribution des prisonniers chez les particuliers pour travailler et ordonner qu'il leur soit accordé « une liberté presque illimitée de se livrer à tous les genres d'industrie utile ${ }^{113}$ ». Il exige, par la même occasion, des rapports sur leur arrivée, leur conduite et l'effet sur la main d'œuvre et les dispositions des ouvriers et journaliers du département ${ }^{114}$. Deux mois plus tard, après la paix de Presbourg et alors que la guerre a pris fin, Fouché prévient qu'à partir du mois d'avril, «il n'existera plus en France de dépôts pour les prisonniers de guerre autrichiens", et que les prisonniers pourront retourner en Allemagne - les officiers de manière isolée, « sur un simple ordre de route", et les soldats, par détachements, accompagnés par la gendarmerie. Cependant, il autorise « ceux d'entr'eux qui désireront ne pas quitter la France » à rester dans le département pour travailler ${ }^{115}$. Pourtant, en décembre de la même année, alors que la guerre a repris contre une quatrième coalition, Pelet envoie une lettre pour ordonner derechef que «ces prisonniers devront être soumis à la surveillance des autorités civiles et militaires, qui feront soigneusement observer leur conduite ${ }^{116} »$.

Dans un contexte de délitement de l'Empire à la fin de la période, ces tensions s'aggravent. En 1811, par exemple, Réal met en garde le préfet de Saône-et-Loire contre les prisonniers de guerre espagnols qui, dans son département, «se permettent de manifester inconsidérément leurs opinions et cherchent à exciter par des déclamations de haine contre la France ${ }^{117} »$. Il ordonne de redoubler de surveillance à leur égard. La correspondance entre autorités locales et centrales, fin 1813 et début 1814, témoigne de la manière dont la perception policière de la dangerosité des prisonniers de guerre s'accroît rapidement, $a$ fortiori quand les alliés ont pénétré sur le sol français. On craint surtout l'augmentation des évasions de ces prisonniers, dont la disparition laisse craindre qu'ils ne fomentent des troubles séditieux, puis, à mesure que les alliés se rapprochent sur le territoire, qu'ils ne viennent grossir l'armée combattante ennemie ${ }^{118}$. L'assurance que ces prisonniers de guerre connaissent finement la région sur le plan géographique comme sur celui de ses ressources - augmente le sentiment de péril imminent des autorités locales, chargés de maîtriser l'agitation de ces étrangers comme les craintes des habitants français ${ }^{119}$.

\section{Conclusion}

Cette étude révèle la prépondérance du nombre des étrangers surveillés préventivement par la police sous le Consulat et l'Empire et leur place centrale dans plusieurs mesures de contrôle policier (détentions par "mesure de haute police", surveillance "spéciale»). Toutefois, sur le terrain, les moyens humains sont souvent insuffisants pour répondre efficacement aux injonctions des autorités. Pour autant, ils démontrent combien la figure de l'étranger suspect est alors protéiforme, prenant, aux yeux de la police, le profil de l'étranger circulant librement en France, du prisonnier de guerre, mais aussi de certains Français soumis à la défiance policière par leur lien à l'étranger: le nouveau Français et l'émigré. In fine, entre 1799 et 1815, l'étranger est rejeté du corps social tant pour des motifs sociaux que politiques, puisqu'il semble constituer autant un élément perçu comme asocial qu'une menace politique pour la survie de l'État. Les fluctuations du contrôle policier à son égard révèlent les évolutions du contexte extérieur militaire et géopolitique, mais aussi les objectifs politiques d'un régime conscient de sa propre fragilité. 


\section{NOTES}

1. Jean-Paul BERTAUD, Quand les enfants parlaient de gloire : l'armée au cœur de la France de Napoléon, Paris, Aubier, 2006; Robert John MORRISSEY, Napoléon et l'héritage de la gloire, Paris, Presses universitaires de France, 2010 ; Alan FORREST : « The Military Culture of Napoleonic France », dans Philip G. DWYER (dir.), Napoleon and Europe, Harlow ; New York, Longman, 2001, p. 43-59.

2. Cette figure de l'« empereur de guerre » peut être comprise comme le retour de la figure du « roi de guerre », qui demeurerait une référence mentale par-delà la Révolution. Joël CORNETTE, Le roi de guerre : essai sur la souveraineté dans la France du Grand siècle, Paris, Payot \& Rivages, 2000.

3. Voir notamment Emmanuel LAS CASES, Le Mémorial de Sainte-Hélène, Paris, Flammarion, 1983, p. 554.

4. Pendant la période révolutionnaire, les mesures répressives concernant les étrangers ont été attribuées au poids de la guerre par Albert Mathiez. Albert MATHIEZ, La Révolution et les étrangers : cosmopolitisme et défense nationale, La Renaissance du Livre, 1918. Sophie Wahnich a révisé cette interprétation: Sophie WAHNICH, L'impossible citoyen: l'étranger dans le discours de la Révolution française, Paris, A. Michel, 1997. Depuis, plusieurs travaux ont été consacrés à la situation des étrangers pendant les guerres révolutionnaires, notamment dans les départements frontaliers. Voir notamment Maxime KACI, «Voisins, patriotes et comploteurs. Les logiques d'une perception fluctuante des "étrangers" au sein des territoires frontaliers du nord et de l'est de la France (1789-1794) », Annales de l'Est, $\mathrm{n}^{\circ}$ 1, 2019, p. 177-197; et le numéro des AHRF consacré à « L'Âge des révolutions: rebonds transnationaux", Annales historiques de la Révolution française, $\mathrm{n}^{\circ} 397$, $3 / 2019$.

5. Xavier RousSEAUX, Jonas CAMPION, « New threats or phantom menace ? Police institutions facing crises ", dans Jonas CAMPION et Xavier Rousseaux (dir.), Policing New Risks in Modern European History, Basingstoke, Palgrave Macmillan, 2016, p. 1-21.

6. AN AFIV 1043, Compte rendu de l'administration de la police générale pendant l'an 8 par le ministre de ce département. Voir à ce propos Aurélien LIGNEREUX, « Le moment terroriste de la chouannerie : des atteintes à l'ordre public aux attentats contre le Premier Consul ", La Révolution française. Cahiers de l'Institut d'histoire de la Révolution française, 1, 2012.

7. Selon les politistes Ayse Ceylan et Gabriel Periès, l'expression «ennemi de l'intérieur » implique non seulement « celui qui est purement intérieur », mais aussi « celui qui se déplace de l'extérieur vers l'intérieur ou celui qui agit depuis l'intérieur où il est infiltré ». Ayse CEYHAN et Gabriel PÉRIÈs, "L'ennemi intérieur : une construction discursive et politique », Cultures \& Conflits, $\mathrm{n}^{\circ} 43,2001$, p. 5-11. Ce concept avait été particulièrement mobilisé pendant la période du Gouvernement révolutionnaire (1793-94). Anne SIMONIN, Le déshonneur dans la République: une histoire de l'indignité, 1791-1958, Paris, B. Grasset, 2008, p. 327. Pour une analyse de l'évolution de l'usage du terme «ennemi » par les révolutionnaires entre 1789 et 1799, voir Jean-Clément MARTIN, «La Révolution française : généalogie de l'ennemi », Raisons politiques, n 5-1, 2002, p. 69-79.

8. Jeanne-Laure LE QUANG, « Haute police, surveillance politique et contrôle social sous le consulat et le Premier Empire (1799-1814) », Annales historiques de la Révolution française, $\mathrm{n}^{\circ}$ 399-1, 2020, p. 215-225. Il faut noter cependant que la surveillance des étrangers ne se limite pas à ces mesures policières spécifiques, mais prend également d'autres formes, comme le contrôle des passeports. Voir notamment Vincent DENIS, Une histoire de l'identité : France, 1715-1815, Seyssel, Champ Vallon, 2008. 
9. Patrick WEIL, Qu'est-ce qu'un Français ? Histoire de la nationalité française depuis la Révolution, Paris, B. Grasset, 2002 ; Gérard NOIRIEL, « Socio-histoire d'un concept. Les usages du mot "nationalité" au XIX siècle ", Genèses. Sciences sociales et histoire, 20-1, 1995, p. 4-23.

10. Sur les questions d'identification, voir Vincent DENIS, Une histoire de l'identité, op. cit., et le dossier spécial «Stratégies et procédures d'identification des étrangers ", Mélanges de la Casa de Velázquez, 51-1, 2021.

11. AN F7 4260.

12. Ces bulletins quotidiens ont été édités : Ernest D’HAUTERIVE (dir.), La police secrète du premier Empire: bulletins quotidiens adressés par Fouché à l'Empereur, Paris, Perrin, 1908-1922, puis Paris, Clavreuil, 1963-1964, 5 tomes ; Nicole GOTTERI (dir.), La police secrète du Premier Empire: bulletins quotidiens adressés par Savary à l'Empereur, Paris, H. Champion, 1997-2004, 7 tomes.

13. Le 12 messidor an VIII ( $1^{\mathrm{er}}$ juillet 1800), un arrêté « détermine les fonctions du préfet de police de Paris ", lui confiant notamment la surveillance des passeports, des cartes de sûreté, des permissions de séjourner à Paris, mais aussi du vagabondage et des garnis.

14. Loi du 28 pluviôse an VIII (17 février 1800).

15. Des commissaires généraux sont établis par l'arrêté du 5 brumaire an IX (27 octobre 1800), puis des commissaires spéciaux sont créés dans certaines villes par le décret du 25 mars 1811 . Pour une description synthétique de l'organisation de la police consulaire et impériale, voir Michel AUBOIN, Arnaud TEYSSIER et Jean TULARD, Histoire et dictionnaire de la police, du Moyen âge à nos jours, Paris, Robert Laffont, coll. «Bouquins », 2005, p. 268-305.

16. Édouard EBEL, Les préfets et le maintien de l'ordre public, en France, au XIX siècle, Paris, la Documentation française, 1999.

17. Aurélien Lignereux, Gendarmes et policiers dans la France de Napoléon: le duel Moncey-Fouché, Maisons-Alfort, Service historique de la gendarmerie nationale, 2002.

18. Le contrôle des étrangers et de leur mobilité n'est évidemment pas une innovation napoléonienne. Voir notamment les articles de Catherine DENYS, Michel PERTUÉ, Jean-Luc LAFFONT et Vincent MILLIOT dans Marie-Claude BLANC-CHALÉARD, Caroline DOUKI, Nicole DYONNET et Vincent MiLlioT (dir.), Police et migrants : France, 1667-1939, Rennes, Presses universitaires de Rennes, 2001 ; Jean-François DUBOST, « Les étrangers à Paris au siècle des Lumières ", dans Daniel Roche (dir.), La ville promise : mobilité et accueil à Paris, fin XVII -début XIX siècle, Paris, Fayard, 2000, p. 220-288; et dans une perspective plus internationale, Olivier CAPOROSSI (dir.), Histoire de la police des étrangers : les expériences atlantiques, $\mathrm{XIV}^{e}-\mathrm{XX}{ }^{e}$ siècle, Paris, les Indes savantes, 2015.

19. Sophie WAHNich, L'impossible citoyen..., op. cit.; Sébastien LAURENT, Politiques de l'ombre: État, renseignement et surveillance en France, Paris, Fayard, 2009, p. 74-76.

20. Décret du $1^{\mathrm{er}}$ août 1793. Michel PERTUÉ, «La police des étrangers sous la Révolution française ", dans Marie-Claude BLANC-CHALÉARD, Caroline DOUKI, Nicole DYONNET et Vincent MiLliot (dir.), Police et migrants..., op. cit., p. 65.

21. Décret du 27 germinal-5 floréal an II (15-24 avril 1794) «concernant la répression des conspirateurs, l'éloignement des nobles, et la police générale ", Recueil général des lois, décrets, ordonnances, etc. depuis le mois de Juin 1789 jusqu'au mois d'Août 1830, Barrot, Administration du Journal des notaires, 1839, p. 239-241.

22. Loi du 23 messidor an III (11 juillet 1795), « décret qui ordonne aux étrangers nés dans les pays avec lesquels la République est en guerre de sortir de France, s'ils n'y sont pas domiciliés, avant le premier janvier $1792 »$.

23. Le cas particulier des réfugiés étrangers ne sera pas abordé ici. Voir Delphine DIAZ, En exil. Les réfugiés en Europe, de la fin du XVIII siècle à nos jours, Paris, Gallimard, 2021.

24. Loi du 28 vendémiaire an VI (19 octobre 1797) : loi relative aux passeports. En outre, le Code pénal de 1810 prévoit (article 272) que les vagabonds de nationalité étrangère pourront être reconduits hors du territoire impérial. 
25. Sous la Révolution, avait été mis en place un système de cartes de sûreté de couleur différente, rouge pour les étrangers, permettant de les distinguer des autres voyageurs. Ce système différencié prend fin en 1806 avec l'adoption du système des passeports uniformes. Vincent DENIS, «Le contrôle de la mobilité à travers les passeports sous l'Empire ", dans MarieClaude BLANC-CHALÉARD, Caroline DOUKI, Nicole DYONNET et Vincent MILLIOT (dir.), Police et migrants..., op. cit., p. 395-415.

26. Vincent DENIS, Une histoire de l'identité, op. cit., p. 308-311.

27. Ibid., p. 282 et 323.

28. Circulaire de Fouché aux préfets sur le rôle de la haute police, lors de son retour au ministère de la Police générale en messidor an XII, Toulouse, les frères Douladoure imprimeurs, 1819.

29. AD Saône-et-Loire M4054, lettre de Fouché à l'administration centrale du département de Saône-et-Loire, 17 frimaire an VIII (8 décembre 1799).

30. AD Saône-et-Loire M4054, lettre de Fouché au préfet de Saône-et-Loire, 19 vendémiaire an X (11 octobre 1801).

31. AN F7 3276, dossier 2 et 12.

32. $\mathrm{AD}$ Saône-et-Loire M4054, lettre de Fouché à l'administration centrale du département de Saône-et-Loire, 17 frimaire an VIII (8 décembre 1799).

33. Marie-Noëlle BOURGUET, Déchiffrer la France : la statistique départementale à l'époque napoléonienne, Paris, Éd. des Archives contemporaines, 1989.

34. Michel PERTUÉ, « La police des étrangers... », art. cité.

35. AN F7 4260, fichier de police qui a fait l'objet d'une étude sérielle systématique.

36. AN F7 6244, Mémoire adressé au préfet de police par le ministre de la police Fouché sur le mode de police dans la commune de Paris, floréal an VIII (mai 1800).

37. Ernest D'HAUTERIVE (dir.), La police secrète..., op. cit., tomes 4 et 5 ; et Nicole GOTTERI (dir.), La police secrète du Premier Empire..., op. cit., tomes 1 à 5. Ces bulletins résultent cependant d'un tri préalable opéré par le ministère de la Police générale parmi ses opérations quotidiennes et ne sont donc pas exhaustifs.

38. Entre 1808 et 1810 , on relève 185 mentions d'étrangers surveillés à Paris dans ces bulletins sur 490 opérations de surveillance mentionnées. Entre 1810 et 1812 , le chiffre tombe à 74 mentions d'étrangers sur 330 opérations de surveillance relatées au total. Il faut souligner que ces chiffres ne correspondent pas à un nombre d'individus différents, mais à une opération de surveillance journalière : les mêmes individus sont fréquemment surveillés pendant plusieurs jours de suite.

39. Voir par exemple AN F7 3053, rapport de police non daté et non signé.

40. AN O2 1430A, Lettre de Fouché à la Commission sénatoriale de la liberté individuelle du 8 brumaire an XIII, au sujet du comte de Wilhem, Allemand.

41. Bulletin du mardi 23 avril 1811, Nicole GOTTERI (dir.), La police secrète du Premier Empire..., op. cit., t. 2, p. 338.

42. AN F7 4260.

43. AN F7 4260.

44. Bulletin du mercredi 21 juin 1809, Ernest D'HAUTERIVE (dir.), La police secrète..., op. cit., t. 5, p. 90.

45. C'est le cas pour la légation russe en 1808. Ernest D'HAUTERIVE (dir.), La police secrète..., op. cit., t. 4, p. 7, 53 et 66 notamment.

46. Les rapports de Veyrat au préfet de Police de Paris Dubois en mai 1809 à ce sujet sont cités par Jean RIGOTARD, La police parisienne de Napoléon : la préfecture de police, Paris, Tallandier, 1990, p. 183. Le parcours hors-norme de l'inspecteur général Veyrat est retracé par Ernest D'HAUTERIVE, Mouchards et policiers, Paris, Gallimard, 1936, p. 141-170.

47. Voir Nicole GOTTERI (dir.), La police secrète du Premier Empire..., op. cit., t. 1.

48. Joseph FouchÉ, Mémoires de Joseph Fouché, Paris, Imprimerie nationale, 1993, p. 246. 
49. Jean-Claude FARCY, Les camps de concentration français de la Première Guerre mondiale (1914-1920), Paris, Anthropos-Economica, 1995 ; Frédéric MÉDARD, Les prisonniers de guerre en 1914-1918. Acteurs méconnus de la Grande Guerre, Paris, 14-18 Éditions, 2010.

50. Jacques-Olivier BOUDON, «L'expérience de la captivité comme forme de contact. Les prisonniers prussiens en France après la campagne de 1806-1807 », dans Jacques-Olivier BoudoN, Gabriele B. CLEMENS, Pierre HORN (dir.), Erbfeinde im Empire? Franzosen und Deutsche im Zeitalter Napoleons, Stuttgart, Thorbecke, 2016, p. 245-262. Ce n'est pas une pratique uniquement française. Voir Renaud MORIEUX, The Society of Prisoners: Anglo-French Wars and Incarceration in the Eighteenth Century, Oxford, Oxford University Press, 2019; Linda COLleY, Captives: Britain, Empire and the World 1600-1850, Londres, Jonathan Cape, 2002.

51. Eman M. vovsI, « “A Long Road Home”: Russian Prisoners in France, 1799-1801 », Napoleonica. La Revue, $\mathrm{n}^{\circ}$ 21, 2014, p. 130-140. Jacques-Olivier BOUDON, «Les prisonniers de guerre russes en France de 1798 à 1856 ", dans ID. (dir.), Le choc des empires. France et Russie, 1798-1870, Paris, Éditions SPM, 2018, p. 83-108 ; ID., "L'expérience de la captivité... », op. cit. ; ID., " Prisonniers de guerre et forçats napolitains en France au lendemain de la conquête du royaume de Naples (1806-1815)», dans Pierre-Marie DELPU, Igor MOULLIER et Mélanie TRAVERSIER, Le royaume de Naples à l'heure française. Revisiter l'histoire $d u$ decennio francese (1806-1815), Villeneuve d'Ascq, Presses universitaires du Septentrion, 2019, p.31-51; David ROUANET, «Les prisonniers de guerre étrangers dans le Nord-Est de la France (1803-1814) ", thèse de doctorat soutenue en 2008 sous la direction de Jacques-Olivier Boudon, Sorbonne Université ; Jean-René AYMES, La déportation sous le premier Empire : les Espagnols en France, 1808-1814, Paris, Publications de la Sorbonne, 1983.

52. En 1800, il y aurait environ 6000 prisonniers russes en France; en 1803, 10000 à 17000 prisonniers anglais; en 1805-1807, 50000 à 90000 Autrichiens, 50000 à 70000 Prussiens, 14000 Russes et plusieurs milliers de Suédois et Napolitains; enfin, 8000 Russes arrivent en France à l'issue de la campagne de Saxe de 1813.

53. La délimitation des attributions respectives de ces deux ministères en matière de gestion des prisonniers de guerre semble floue, car non codifiée.

54. Les Anglais ont un statut à part : considérés comme des prisonniers de guerre au moment de la reprise de la guerre contre l'Angleterre au début de la période, les Anglais résidant dans les départements côtiers sont assignés à résidence dans des villes éloignées de la côte, puis expulsés de ces départements pour la plupart pour être amenés dans des villes de l'intérieur. Vincent CUVILLIERS, «Des "Empereurs au petit pied" entre exigences gouvernementales et résistances départementales : l'exemple des préfets du Pas-de-Calais (1800-1815) », thèse inédite de doctorat soutenue en 2009 sous la direction d'Annie Crépin, chapitre 8.

55. Des prisonniers de guerre napolitains sont placés dans les départements italiens de l'Empire en 1803, mais ils y alimentent de nombreux troubles à l'ordre public (insurrections, évasions, brigandage). Jacques-Olivier BOUDON, «Prisonniers de guerre et forçats napolitains...», contribution citée, p. 35.

56. AD Saône-et-Loire, 9R1 à 9R4.

57. AD Saône-et-Loire 9R1, règlement du 6 vendémiaire an XIV (28 septembre 1805) intitulé " pour la police et la discipline des Prisonniers de guerre ", émanant du ministère de la Guerre.

58. AD Saône-et-Loire 9R1, lettre du chef de l'État-major de la $18^{\mathrm{e}}$ division militaire au préfet de Saône-et-Loire, 16 mai 1809.

59. Un témoignage de ces conditions de vie est donné par Moritz von KOTZEBUE, The Russian Prisoner of War Among the French, Londres, Hamilton, 1816.

60. Jacques-Olivier BOUDON, «Les prisonniers de guerre russes en France... », contribution citée, p. 87.

61. Ibid., p. 31.

62. Décret du 17 juillet 1806 « concernant les forçats libérés ». 
63. $\mathrm{AD}$ Saône-et-Loire $9 \mathrm{R} 1$, règlement pour la répartition, la police et le traitement des prisonniers de guerre employés aux travaux de l'État ou chez les particuliers, 12 brumaire an XIV (3 novembre 1805).

64. AD Saône-et-Loire 9R1.

65. AD Saône-et-Loire M91, Lettre du conseiller d'État chargé du $3^{\mathrm{e}}$ arrondissement de la police générale de l'Empire (Pelet) au préfet de Saône-et-Loire, 21 novembre 1806, qui annonce que sur ces 2000 Napolitains, la Saône-et-Loire en recevra 50, destinés aux travaux de ce département.

66. Jacques-Olivier BOUDON, « Prisonniers de guerre et forçats napolitains... ", art. cité, p. 42-49.

67. AD Saône-et-Loire M4054, circulaire de Fouché aux préfets, $1^{\text {er }}$ octobre 1808.

68. AD Saône-et-Loire M4054.

69. Jeanne-Laure LE QUANG, «Administrer l'exil intérieur : l'envoi en "surveillance spéciale" sous le Consulat et le Premier Empire (1799-1815) », dans Gilles BERTRAND, Catherine BRICE et Mario INFELISE, Exil, asile: du droit aux pratiques, XVIe-XIXe siècle, Rome, Publications de l'École Française de Rome, 2022, p. 266-277 (à paraître).

70. $A D$ Saône-et-Loire $9 R 1$, règlement pour la répartition, la police et le traitement des prisonniers de guerre employés aux travaux de l'État ou chez les particuliers, 12 brumaire an XIV (3 novembre 1805).

71. Jacques-Olivier BOUDON, "L'expérience de la captivité comme forme de contact...», contribution citée.

72. AD Saône-et-Loire 9R3, instructions de Pelet de la Lozère aux préfets, $1^{\mathrm{er}}$ mars 1810.

73. On prolonge ici un questionnement initié par Aurélien LIGNEREUX, L'Empire des Français, 1799-1815, Paris, Éd. du Seuil, 2012, p. 260-267. Demeure notamment une incertitude sur la place des régiments étrangers dans la Grande Armée : Jean-François BRUN, « Les unités étrangères dans les armées napoléoniennes: un élément de la stratégie globale du Grand Empire", Revue historique des armées, $\mathrm{n}^{\circ} 255,2009$, p. 22-49; Bernard GAINOT, «L'emploi des régiments étrangers dans la Grande Armée : l'exemple du régiment de La Tour d'Auvergne », dans Hervé DRÉviLloN, Bertrand FONCK, Michel ROUCAUD (dir.), Guerres et armées napoléoniennes: nouveaux regards, Paris, Nouveau Monde éd. ; Fondation Napoléon, 2013, p. 207-236.

74. Notamment Aurélien LIGNEREUX, Les impériaux : administrer et habiter l'Europe de Napoléon, Paris, Fayard, 2019; Michael BROERS, The Napoleonic Empire in Italy, 1796-1814: Cultural Imperialism in a European Context?, Basingstoke, Palgrave Macmillan, 2005; Stuart Joseph Woolf, Napoleon's Integration of Europe, Londres, Routledge, 1991; Christine PEYRARD, Francis POMPONI et Michel VOVELLE (dir.), L'administration napoléonienne en Europe: adhésions et résistances, Aix-en-Provence, Publications de l'Université de Provence, 2008.

75. L'obsession policière à l'égard des Italiens semble héritée de la période révolutionnaire. Richard СовB, La protestation populaire en France : 1789-1820, Paris, Calmann-Lévy, 1975 ; Anna Maria RAO, Esuli : l'emigrazione politica italiana in Francia (1792-1802), Naples, Guida, 1992.

76. AN F7 4260.

77. AN AFIV 1043, Compte-rendu de l'administration de la Police générale pendant l'an VIII par le ministre de ce département.

78. AD Saône-et-Loire M91, Lettre du conseiller d'État chargé du $2^{\mathrm{e}}$ arrondissement de la police générale de l'Empire au préfet de Saône-et-Loire, 28 fructidor an XIII (15 septembre 1805).

79. Aurélien LIGNEREUX, Servir Napoléon: policiers et gendarmes dans les départements annexés, 1796-1814, Seyssel, Champ Vallon, 2012, p. 275-293. L'annexion de ces espaces s'est souvent accompagnée de mesures d'ordre expéditives, ce qui explique aussi la persistance de la suspicion à l'égard de populations soumises en partie par la force. Michael BROERS, « Policing the Empire: Napoléon and the Pacification of Europe », dans Philip G. DWYER (dir.), Napoleon and Europe, op. cit., p. 153-168. 
80. Michael BROERS, « La gendarmerie et le maintien de l'ordre public dans l'Italie napoléonienne, 1800-1814. Institutions françaises et société baroque: la culture et la police ", dans Xavier RousSEAUX, Marie-Sylvie DuPONT-BOUCHAT, Claude VAEL (dir.), Révolutions et justice pénale en Europe : modèles français et traditions nationales, 1780-1830, Paris, L'Harmattan, 1999, p. 179-187.

81. Il faut souligner toute l'ambiguïté de ce terme de «brigands", relevant tantôt de la délinquance ordinaire, tantôt d'actes de rébellion ayant une portée politique. Valérie SOTTOCASA (dir.), Les brigands: criminalité et protestation politique, 1750-1850. Actes du colloque de Toulouse, [24-25] mai 2007, Rennes, Presses universitaires de Rennes, 2013.

82. AN F7 4260.

83. Plusieurs fiches de police attestent de l'envoi privilégié des Italiens suspects à Fenestrelle. AN F7 4260, notamment les fiches de Saint Laurent, Jean Gallo et Charges Guggia. Voir aussi le dossier concernant Fenestrelle en AN F7 3294.

84. Jean-Claude VIMONT, La prison politique en France: genèse d'un mode d'incarcération spécifique, XVIII ${ }^{e}$-XXe siècles, Paris, Anthropos, 1993, p. 90.

85. Jeanne-Laure LE QUANG, «La Commission sénatoriale de la liberté individuelle face aux mesures de haute police (1804-1814) : loi intégrée, loi contournée? ", Annales historiques de la Révolution française, $\mathrm{n}^{\circ}$ 394, 2018, p. 79-104.

86. Statistiques élaborées à partir des dossiers conservés en AN 02 1430-1436.

87. AN F7 6540, $\mathrm{n}^{\circ}$ 1763, Mission de Réal en Belgique et en Hollande; troubles dans la Sarre (1809-1811). Voir aussi Antoine RENGLET, « Des polices en quête de modernité ? Systèmes policiers et ordre public dans les villes de l'espace belge de la fin de l'Ancien Régime à la fin de l'Empire napoléonien (1780-1814)", thèse soutenue en 2016 à l'université de Lille et à l'université de Namur, dirigée par Catherine Denys et Axel Tixhon.

88. AN O2 1434, dossier n 396, Mémoire collectif adressé à Napoléon, signé « Thiéry, rédacteur ", envoyé à la Commission sénatoriale de la liberté individuelle, émanant du département du MontTonnerre, non daté [1810].

89. AD Saône-et-Loire M91, M4054, M4230 et M1507.

90. AN F7 8745, état des individus en surveillance spéciale au $1^{\mathrm{er}}$ avril 1811.

91. On reprend la belle formule de Sophie WAHNich, L'impossible citoyen..., op. cit.

92. Anne SimONin, Le déshonneur dans la République..., op. cit., p. 318.

93. Notamment par l'arrêté du 27 février 1800 (7 ventôse an VIII) qui autorise certaines radiations pour tous les prévenus d'émigration qui auraient réclamé contre leur inscription avant le 25 décembre 1799.

94. Titre $\mathrm{I}^{\mathrm{er}}$, article 4 .

95. Articles 76 à 85, 207 et 208.

96. Titre $\mathrm{I}^{\mathrm{er}}$, article 12 .

97. AN AFIV 1043, rapport aux Consuls du ministre de la Police générale, non daté [messidor an VIII].

98. Fouché insiste dans diverses circulaires sur l'idée que les anciens émigrés menacent « l'inaliénabilité des biens nationaux ». Emmanuel de WARESQUIEL, «Joseph Fouché et la question de l'amnistie des émigrés (1799-1802) », Annales historiques de la Révolution française, $\mathrm{n}^{\circ} 372,2013$, p. $105-120$.

99. AN AFIV 1043, rapport aux Consuls, Fouché, non daté, [messidor an VIII].

100. Notamment, les circulaires du 27 vendémiaire an V (18 octobre 1796), 12 thermidor an VIII (31 juillet 1800), 8 ventôse an X (27 février 1802), 14 fructidor an XII ( ${ }^{\mathrm{er}}$ septembre 1804) et 28 fructidor an XIII (15 septembre 1805), conservées en AD Saône-et-Loire 1 L 839 et M91.

101. Au contraire, le sénatus-consulte de floréal an $X$ intervenait dans un contexte de paix et insistait lui-même sur cet aspect pour justifier l'amnistie, affirmant la nécessité de "cimenter » la paix par des mesures de ralliement des Français. Bulletin des Lois de la République française, $3^{e}$ 
série, t. VI: Contenant les Lois et Arrêtés rendus pendant le second semestre de l'an X ( ${ }^{\text {os }} 171$ à 219$)$, Paris, Impr. de la République, X (1802), $\mathrm{n}^{\circ}$ 178, p. 107-112.

102. AD Saône-et-Loire M91, lettre de Miot, conseiller d'État chargé du $2^{\mathrm{e}}$ arrondissement de la police générale de l'Empire au préfet de Saône-et-Loire, 14 fructidor an XII ( $1^{\mathrm{er}}$ septembre 1804).

103. Ibid.

104. AN F7 4260. En outre, Fouché indique dans un rapport aux Consuls de brumaire an VIII qu'il a placé 1590 émigrés en surveillance. AN, 284 AP16, Papiers Sieyès, Rapport du ministre de la Police aux Consuls, non daté (brumaire an VIII), cité par Emmanuel DE WARESQUIEL, «Joseph Fouché et la question... ", art. cité.

105. Nicole GOTTERI (dir.), La police secrète du Premier Empire, op. cit., t. 1, p. 70.

106. F7 7012, Lettre du préfet de Police de Paris Dubois au ministre de la Police, du 29 octobre 1806.

107. Un exemple similaire est le parcours de Gatecher, ancien émigré en Pologne, placé à son retour en détention par «mesure de haute police " pour soupçon d'espionnage par Fouché. AN O2 1430A, dossier $n^{\circ} 57$, lettre de Fouché à la Commission sénatoriale de la liberté individuelle, 4 thermidor an XII (23 juillet 1804). Sur 487 pétitionnaires, les dossiers de la Commission sénatoriale de la liberté individuelle renferment 21 anciens émigrés (4\%).

108. L'expression est empruntée à Simona CERUTTI, Étrangers : étude d'une condition d'incertitude dans une société d'Ancien régime, Montrouge, Bayard, 2012.

109. On trouve 15 mentions de Russes surveillés dans les Bulletins quotidiens entre octobre et décembre 1808, puis 26 dans les 6 mois suivants. Ernest D'HAUTERIVE (dir.), La police secrète..., op. cit., t. 4

110. Bulletin du lundi 17 octobre 1808, ibid., p. 404.

111. AD Saône-et-Loire M4054, Circulaire de Fouché aux préfets, $1^{\mathrm{er}}$ octobre 1808.

112. Bulletin du vendredi 8 janvier 1808, Ernest D’HAUTERIVE (dir.), La police secrète..., op. cit., t. 4, p. 7.

113. AD Saône-et-Loire M4054, lettre de Pelet au préfet de Saône-et-Loire, 2 frimaire an XIV (23 novembre 1805).

114. De même, en 1810, Pelet exige d'avoir tous les quinze jours un état des prisonniers de guerre et d'État, et de leur esprit. AD Saône-et-Loire 9R3, instructions de Pelet aux préfets, $1^{\mathrm{er}}$ mars 1810. 115. AD Saône-et-Loire M91, Lettre de Fouché au préfet de Saône-et-Loire, 21 février 1806.

116. AD Saône-et-Loire M4054, lettre de Pelet au préfet de Saône-et-Loire, 10 décembre 1806. 117. AD Saône-et-Loire M91, lettre de Réal au préfet de Saône-et-Loire, 21 novembre 1811.

118. De fait, ces évasions augmentent. Pour le département de Saône-et-Loire, on note trois prisonniers de guerre évadés en 1811, cinq en 1812, mais vingt-trois en 1813. En 1814, le compte n'est plus possible, mais, en janvier, 96 prisonniers du seul dépôt de Louhans ont déserté. Statistique faite d'après les papiers conservés en AD Saône-et-Loire 9R1.

119. Dans le cas de Chalon-sur-Saône, le sous-préfet décide de calmer l'agitation en faisant verser leur solde à tous les prisonniers, AD Saône-et-Loire 9R1.

\section{RÉSUMÉS}

Dans un contexte de guerre quasi omniprésent, la gestion de la présence d'étrangers sur le sol français constitue un enjeu majeur pour la police napoléonienne. Demeurent présents en France 
quelques centaines de nobles et diplomates, mais également des milliers de prisonniers de guerre. Largement exclus du corps social et perçus avec méfiance par les autorités napoléoniennes, la présence de ces étrangers est tolérée et étroitement encadrée par le biais de "mesures de haute police », allant de la surveillance préventive à l'envoi en détention ou en résidence surveillée. Au-delà des seuls individus de nationalité étrangère, l'article questionne les contours mêmes de ce qui est perçu comme "étranger» dans un Empire en forte expansion territoriale, en mettant à jour l'appréhension problématique par la police des «nouveaux Français » vivant dans les départements annexés, mais aussi des émigrés.

In a context of almost omnipresent war, managing the presence of foreigners on French soil was a major challenge for the Napoleonic police. A few hundred nobles and diplomats remained in France, as well as thousands of prisoners of war. Largely excluded from society and viewed with suspicion by the Napoleonic authorities, the presence of these foreigners was tolerated and closely supervised by means of "high police measures", ranging from preventive surveillance to detention or house arrest. Beyond the scope of individuals of foreign nationality, the article questions the very contours of what is perceived as "foreign" in an Empire undergoing strong territorial expansion, by revealing the problematic apprehension by the police of the "new French" living in the annexed departments, but also of emigrants.

\section{INDEX}

Mots-clés : Étranger, Napoléon Premier, Surveillance, Police, Prison, Émigration, Prisonnier de guerre, Soupçon

Keywords : Stranger, Napoleon the First, Surveillance, Police, Prison, Emigration, Prisoner of war, Suspicion

\section{AUTEUR}

\section{JEANNE-LAURE LE QUANG}

Université Paris 1 Panthéon-Sorbonne

IHMC-IHRF 